\title{
High Temperature Oxidation of Cr-25Nb Alloy Synthesized by Mechanical Alloying and Hot Pressing
}

\author{
Xiao-Wu Nie*, Chun-Lin Niu, Min Ouyang and Hai-Yan Tang \\ Department of Scientific Research, Hunan Railway College of Science and Technology, Zhuzhou 412000, P.R. China
}

\begin{abstract}
Cr}-25 \mathrm{Nb}$ alloy was prepared by mechanical alloying (MA) and hot pressing (HP), and the influences of milling time on the density and oxidation property of samples were investigated. During the studying of the effect of different ball grinding time on oxidation resistance, we discover that the relative density of the $\mathrm{Cr}-25 \mathrm{Nb}$ alloy would increase with the ball grinding time increasing, but when it was oxidized at $1200^{\circ} \mathrm{C}$ for $5 \mathrm{~h}$ in the air, the gain weight rate of the oxidized samples does not only decreased with the ball milling time increasing. In the period of MA 0 to $20 \mathrm{~h}$, the gain weight rate of the oxidized samples reduced with the ball milling time increasing. When the ball milling time further increased, the gain weight rate increased and the oxidation resistance of samples went down. Thus, the oxidation resistance of sample of MA 20 is best. The oxide layer appearance of MA 15 h, MA 20 h, MA 35 h were observed by SEM, respectively. It is found that the oxide layer thickness of specimen of MA 20 hour is thinnest. From the result of EDS and $\mathrm{XRD}_{2} \mathrm{Cr}_{2} \mathrm{O}_{3}$ was formed on the outer oxide layer. However, the oxides in the inner layer were mainly $\mathrm{Cr}_{2} \mathrm{O}_{3}$ and $\mathrm{CrNbO}_{4}$.
\end{abstract}

Keywords: $\mathrm{Cr}-25 \mathrm{Nb}$ alloy, mechanical alloying, oxidation behavior.

\section{INTRODUCTION}

The Laves phase $\mathrm{NbCr}_{2}$ alloy has a great potential for high temperature structural applications due to its high melting temperature, appreciable creep resistance, relatively low density $\left(7.7 \mathrm{~g} / \mathrm{cm}^{3}\right)$, and high strength [1-5]. However, there has been a wide research activity in intermetallics in the last years, commercial utilization of $\mathrm{NbCr}_{2}$ was hampered because it is very brittle at low temperature, like other intermetallics. Therefore, many researches have been done to improve fracture toughness of $\mathrm{NbCr}_{2}$ in material design and preparing technique. As reported by Takasugi et al. [6-8], one route to improve the deformability of $\mathrm{NbCr}_{2}$ is through alloy additions. For example, the addition of Mo to $\mathrm{NbCr}_{2}$ Laves phase compound was shown to be effective in improving the compressive deformability at high temperature [6]. In the past few decades, some attempts to improve the mechanical properties of $\mathrm{NbCr}_{2}$ Laves phase alloys have been performed, such as the ductile-phase [9], addition of other elements [10-12], and so on. Especially, the ambient fracture toughness has been achieved $20 \mathrm{MPa} \cdot \mathrm{m}^{1 / 2}$ for Ti-modified $\mathrm{Nb}(\mathrm{Cr})-\mathrm{NbCr}_{2}$ in-situ composites [9]. However, although the $\mathrm{Nb}(\mathrm{Cr}, \mathrm{Ti})$ matrix phase is ductile, it is not oxidation resistant and, furthermore, is likely susceptible to oxygen embrittlement during elevated temperature exposure in air [13].

A number of studies mentioned above have been conducted using arc-melted buttons. It is well known that mechanical properties of alloys are affected by adopted fabrication technique. Mechanical alloying (MA) has shown to be a promising synthesis technique for materials with highmelting temperature [14]. MA is a high-energy ball milling technique for production of microscopically homogeneous

*Address correspondence to this author at the Department of Scientific Research, Hunan Railway College of Science and Technology, Zhuzhou 412000, P.R. China; Tel: +86-733-2777049; Fax: +86-733-277049;

E-mail: niexiaowu6567@sina.com, niexiaowu6567@163.com materials starting from blended elemental powder mixtures. Many high temperature melting intermetallics that are difficult to prepare by conventional processing techniques could be easily synthesized with better mechanical properties by the MA process followed by hot pressing (HP). In this method, it is easy to realize the approaches of controlling the microstructure to enhance the ductility of Laves phase $\mathrm{NbCr}_{2}$. There are a large number of reports on behavior of conventionally cast $\mathrm{NbCr}_{2}$ in the past decades, but few studies have been carried out on MA and HP materials consolidated $[15,16]$.

In this study, the fabrication of $\mathrm{Cr}-25 \mathrm{Nb}$ alloy by $\mathrm{HP}$ from mechanically alloyed powders and the influence of milling time on the oxidation resistance of alloy at $1200^{\circ} \mathrm{C}$ were investigated.

\section{EXPERIMENTAL}

High-purity crystalline powders of $\mathrm{Nb}(99.9 \%$, $200 \mathrm{mesh})$ and $\mathrm{Cr}(99.9 \%,-200 \mathrm{mesh})$ in a molar ratio of $1: 3$ (i.e., $75 \mathrm{Cr}-25 \mathrm{Nb}$ ) were milled in vacuum for periods up to 50 h. The milling was carried out in a planetary ball-mill (QM1SP ) with both vial and balls made of hardened steel. To reduce oxidation of powders during mechanical alloying, the mechanical alloying was performed in vacuum. Milling parameters such as ball-to-powder mass ratio (13:1) and speed rotation $(400 \mathrm{rpm})$ were kept constant throughout the experiments. During the milling, the powders are liable to adhere to the wall of the pot due to the so called cold welding effect, causing the decreased milling efficiency or even uncompleted milling. The pot was therefore taken into a glove box every $5 \mathrm{~h}$ to remove the adherent powders from the pot wall and to break the agglomerated powders. The powders were taken in a graphite mould with $14 \mathrm{~mm}$ diameter and hot-pressed under $45 \mathrm{MPa}$ for $0.5 \mathrm{~h}$ at $1523 \mathrm{~K}$ in conditions of vacuum. 
The density of the hot pressed samples was determined by the immersion method in distilled water, based on Archimedes principle. The relative density has been calculated by relating these values to the theoretical density. The powders samples were examined by X-ray diffraction (XRD) and scanning electron microscopy (SEM). Cross-section of the oxidized specimens was investigated by SEM. XRD data was collected at a slow scan rate of $0.005 \%$ for the careful determination of average crystallite size and internal strain using Williamson-Hall method and the method is suggested by Ungar et al. [17, 18].

Oxidation property was evaluated using the hot pressing specimens. Their surfaces were abraded on fine $\mathrm{SiC}$ paper, and were washed in running water and ultrasonically cleaned with alcohol. Oxidation tests were performed in air at 1473 $\mathrm{K}$ until $5 \mathrm{~h}$. The samples were place in an alumina crucible $(30 \mathrm{~mm}$ diameter), and the weight changes were monitored by a balance of Sartorius Type BT224S (sensitivity $0.1 \mathrm{mg}$ ).

\section{RESULTS AND DISCUSSION}

\subsection{Analysis of Powders}

The diffraction patterns of elemental mixture powders and as-milled powders are shown in Fig. (1). At the early stage of milling, crystalline $\mathrm{Nb}$ and $\mathrm{Cr}$ peaks were observed. It can be seen that mechanical alloying leads to significant broadening of X-ray diffraction peaks after $20 \mathrm{~h}$ milling, indicating the formation of fine grain and a high density of defects caused by large local strains in the powder particles (as shown in Fig. 2a, b). The broadening of X-ray diffraction peaks is associated with the refinement of grain size. At the very beginning of milling, MA leads to a fast decrease of the grain size. XRD patterns do not exclude an amorphous structure (especially MA 35).

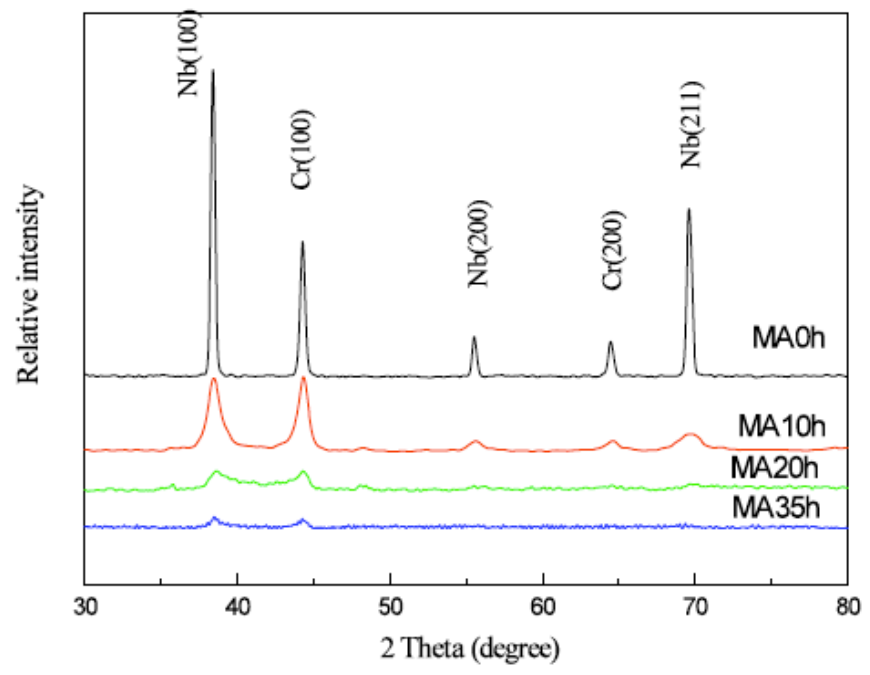

Fig. (1). X-ray diffraction patterns of elemental mixture powders and as-milled powders.

Because a part of $\mathrm{Nb}$ atoms dissolved into the $\mathrm{Cr}$ lattices, the peaks of $\mathrm{Cr}$ were lightly shifted to low angle (the lattice constants changed from $2.8845 \AA$ to $2.8901 \AA$, calculated from XRD results) and the $\mathrm{Nb}$ peaks were weakened. It agrees with the previous results that supersaturated solution $\mathrm{Cr}(\mathrm{Nb})$ had been formed by mechanical alloying.
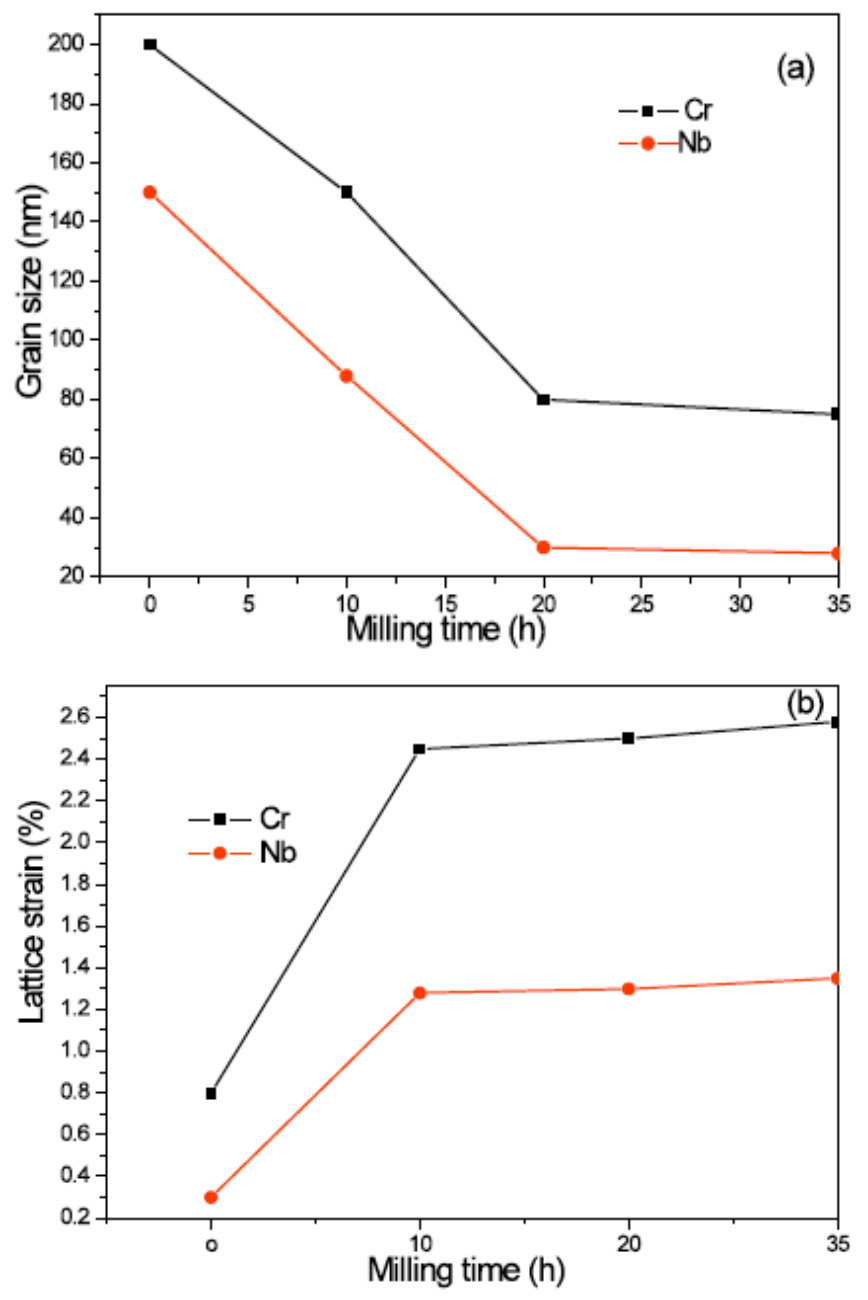

Fig. (2). Variation of grain size (a) and lattice strain (b) with MA time.

The typical SEM micrograph of elemental mixture powders is shown in Fig. (3a). The powders have irregular shapes and various sizes. The mean size of particles is about $20 \mu \mathrm{m}$. Fig. (3b) shows the micrograph of as-milled powders. It can be seen that the size of particles is about $3 \mu \mathrm{m}$, which tend to be uniform. After $20 \mathrm{~h}$ milling, the particles are refined, but some of particles appear large blocks. During the ball milling, the $\mathrm{Nb}$ particles were collided into slices due to their excellent ductility. The $\mathrm{Nb}$ slices gradually turn large through welding fine $\mathrm{Cr}$ particles around them. Though refining action occurs simultaneously, the welding plays a dominant role in this procedure. The milled powders are more homogenous than elemental powders from the EDX analysis. The distributions of elements of $\mathrm{Nb}$ and $\mathrm{Cr}$ are similar for all milled powders.

\subsection{Density of Hot-Pressed Samples}

Fig. (4) shows the influence of milling time on the relative density of samples. It can be clearly seen that all of the densities of the samples is above $94 \%$ of the theoretical density of $\mathrm{Cr}-25 \mathrm{Nb}$ and the relative densities increase with the milling time increasing. Till to $50 \mathrm{~h}$, the relative density is up to $98 \%$. The results indicate the specimens are more and more compact with longer milling time under the same hot 

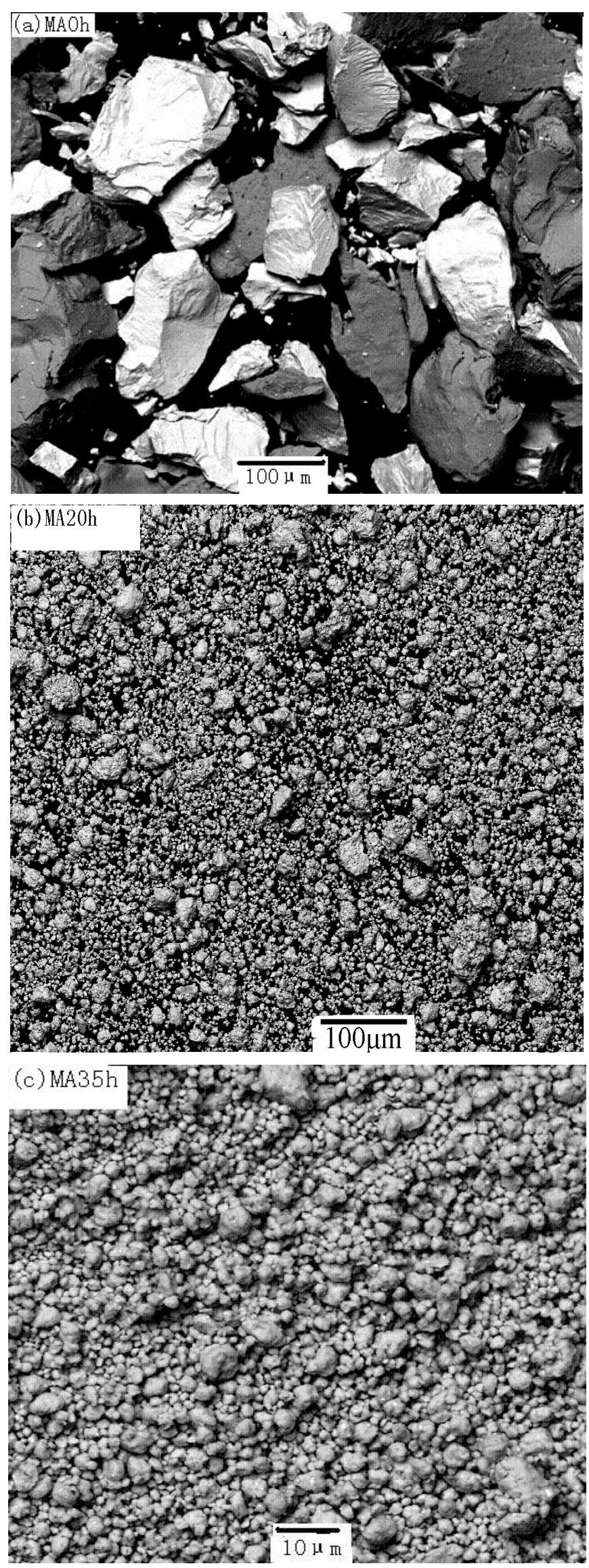

Fig. (3). The SEM micrographs of powders. (a) Elemental powders; (b) ball milling for $20 \mathrm{~h}$; (c) ball milling for $35 \mathrm{~h}$. pressing condition. The increase of densities is possibly attributed to the powders refined with the milling time increasing, the particles are smaller, which leads to easy diffusion in the hot pressing process. Consequently, the relatively densities increase with the milling time increasing.

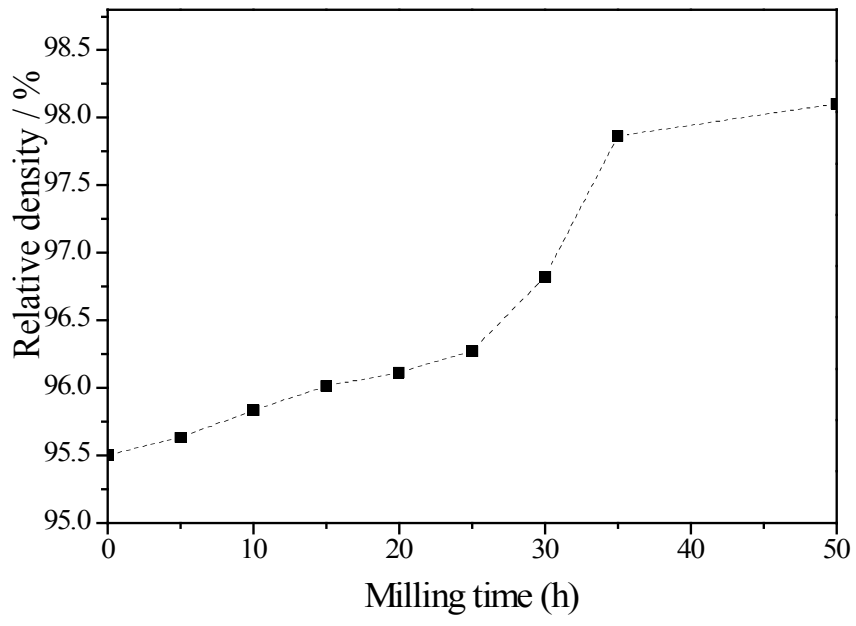

Fig. (4). Relative density of samples as a function of milling time.

\subsection{Oxidation}

Fig. (5) shows the influence of milling time on the weight changes of $\mathrm{Cr}-25 \mathrm{Nb}$ alloys in air at $1473 \mathrm{k}$ for $5 \mathrm{~h}$. As can be seen from Fig. (5), the weight gain reduces and reaches its minimum when the milling time is for $20 \mathrm{~h}$, followed increase. This can be explained by the following: Firstly, Kofstad and Lillerud [19] considered the microcracks transport processes are concluded to be significant during the initial oxidation period. However, as have been known the density of specimens increase with increasing milling time during the hot pressing process, seen in Fig. (4). This is attributed to that there are few microcracks, that is to say few diffusion paths for $\mathrm{Cr}$ or $\mathrm{Nb}$ and oxygen. So, the weight gain reduces with creasing the density of specimens. Secondly, mechanical alloying can be used to produce materials with extremely fine grain sizes. The most direct effect of the strong reduction of the grain size obtainable by this method is the appearance of large concentrations grain boundaries that act as diffusion paths and increase the rate transportation of the alloy components in the presence of chemical potential gradients. In addition, a possible additional effect of mechanical alloying in the case of $\mathrm{Cr}-\mathrm{Nb}$ alloys is related to an increase of the mutual solubility of the alloy components, as observed in a number of cases. This trend to reduce the critical content of the most reactive component $\mathrm{Cr}$ required to sustaining the exclusive external growth of its oxide. All these factors can contribute to provide a more efficient supply of $\mathrm{Cr}$ to the alloy/scale interface needed to form and to maintain protective external $\mathrm{Cr}_{2} \mathrm{O}_{3}$ scales. However, in the early stages (transient oxidation) before the steady-state scale is achieved, both $\mathrm{Cr}$ and $\mathrm{Nb}$ oxidize. With the reducing of the grain size, the grain boundary diffusion of $\mathrm{Nb}$ is enhanced. Based on the aforesaid reasons, the weight gain reduces with the milling time increasing before $20 \mathrm{~h}$, and followed increase. It can be concluded fine grain can improve the oxidation resistance, and maybe has a negative influence on the oxidation resistance when the grain size is more refined. 


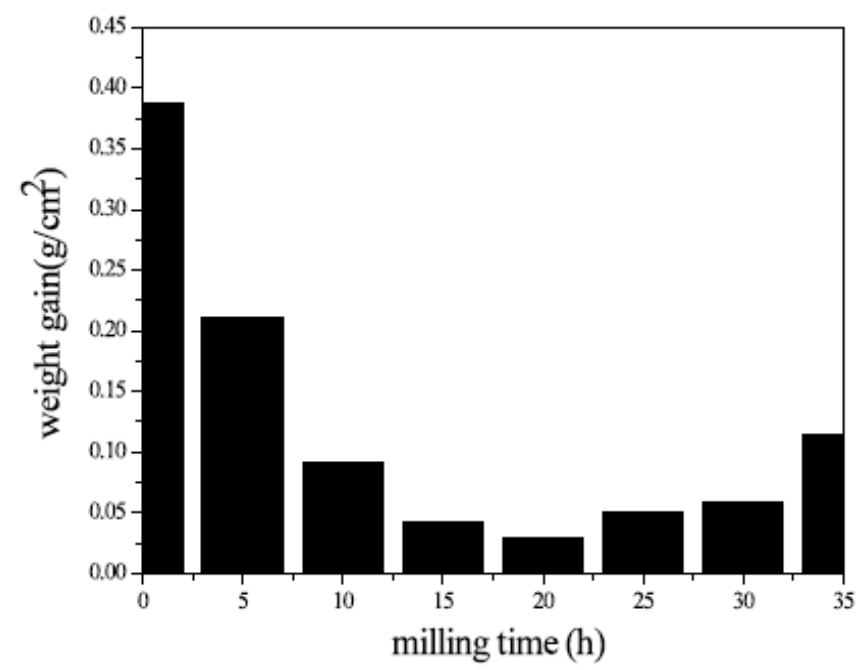

Fig. (5). Weight change versus milling time for $\mathrm{Cr}-25 \mathrm{Nb}$ alloys isothermally oxidized at $1473 \mathrm{~K}$ in air.

\subsection{SEM Image of Oxidized Specimens}

Oxidized cross-section images of $\mathrm{Cr}-25 \mathrm{Nb}$ alloy milled for 15, 20 and 35h, respectively, are shown in Fig. (6). It can be clearly seen that the oxidation layers of the three specimens are like plate and porous. With the EDX, it can be know that the predominately oxide phase of a compositional corresponding to $\mathrm{CrNbO}_{4}$. The outer scale spilt is $\mathrm{Cr}_{2} \mathrm{O}_{3}$. The difference in SEM images is the thickness of the oxidized layer. The thick of these three specimens is about $60 \mu \mathrm{m}$, $40 \mu \mathrm{m}$ and $50 \mu \mathrm{m}$, respectively. It can be seen that the oxidized layer thick of the as-MAed specimen for $20 \mathrm{~h}$ is thinner than those of the other specimen. The result is consistence with the influence of milling time on the weight gain shown in Fig. (5). To interpret this, an effective diffusivity of $\mathrm{Cr}\left(\mathrm{D}_{\text {eff }}\right)$ is proposed, which is a summation of lattice diffusivity $\left(\mathrm{D}_{\mathrm{L}}\right)$ and grain boundary diffusion $\left(\mathrm{D}_{\mathrm{GB}}\right)$ of $\mathrm{Cr}$ in the alloy as given below [20]

$$
D_{e f f}=(1-f) D_{L}+f D_{G B}
$$

where, $f$ is the area proportion of grain boundary. Assuming the grains are cubic, $f=2 \delta / d$ ( $\delta$ is the GB width and $d$ is the grain size). Also, considering $\mathrm{D}_{\mathrm{GB}} \gg \mathrm{D}_{\mathrm{L}}$, Eq. (1) can be simplified as

$$
D_{\text {eff }}=D_{L}+\frac{2 \delta}{d} D_{G B}
$$

Hence, $D_{\text {eff }}$ increases with decreasing $d$. The enhanced grain boundary diffusion prevented the $\mathrm{Cr}$ depletion at the scale-metal interface due to the $\mathrm{Cr}$ consumption by oxidation and simultaneously by vaporization.

\section{CONCLUSION}

In the study of the effect of milling time on oxidation resistance, the results show that the relatively density of $\mathrm{Cr}$ $25 \mathrm{Nb}$ alloy increases with the ball grinding time increasing. When it was oxidized at $1200^{\circ} \mathrm{C}$ for $5 \mathrm{~h}$ in the air, the gain weight rate of the oxidized samples does not only decreased with the ball milling time increasing. In the period of MA 0 to $20 \mathrm{~h}$, the gain weigh rate of the oxidized samples reduced with the ball milling time increasing, that is to say, the
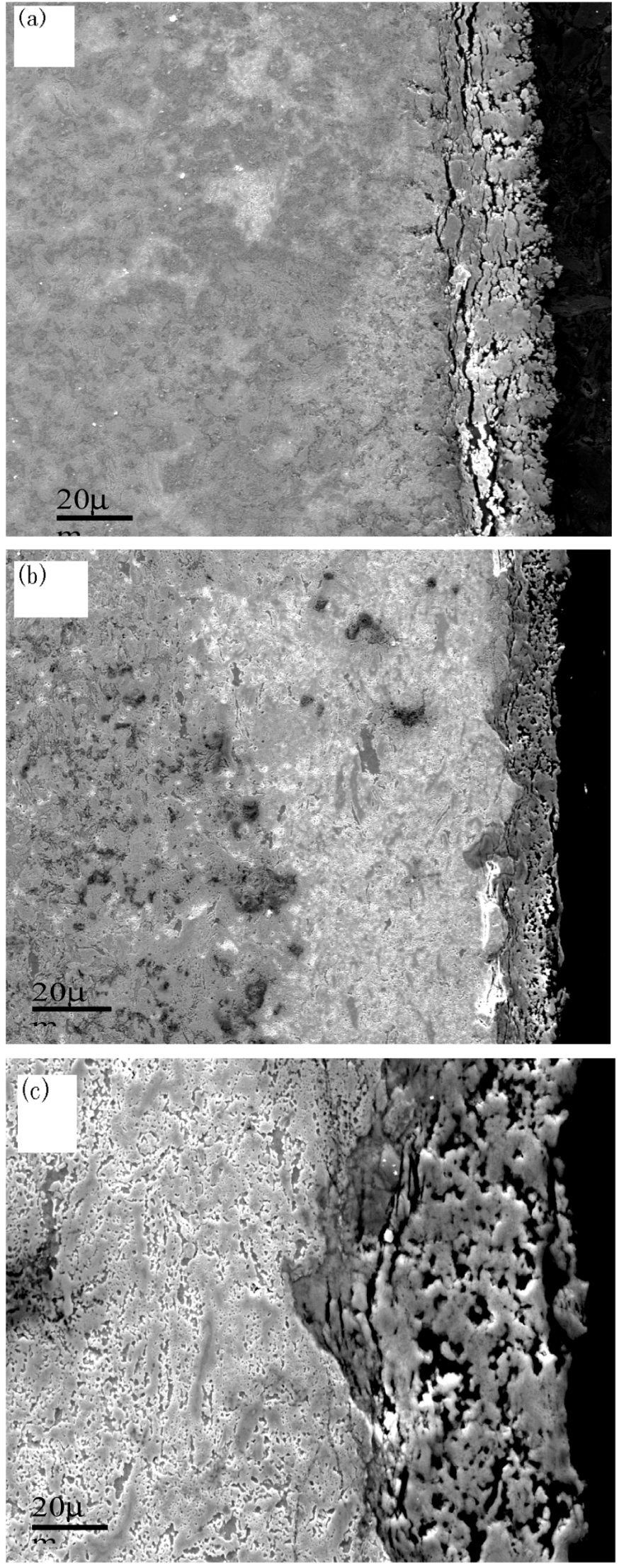

Fig. (6). SEM (secondary electron) cross-section micrograph of the oxide layer of Cr-25Nb alloys milled for (a) $15 \mathrm{~h}$; (b) 20h; (c) $35 \mathrm{~h}$.

oxidation resistance has been improved. When the ball milling time further increased, the gain weight rate increased and 
the oxidation resistance of samples went down. Thus it is showed that the oxidation resistance of sample of MA 20 is best. The oxide layer appearance and the structure of specimens of MA15, MA 20, MA $35 \mathrm{~h}$ were observed by SEM, respectively. It is found that the oxide layer thickness of specimen of MA 20 hour is thinnest, which displayed the high temperature oxidation resistance was better; From the results of energy spectrum analysis and $\mathrm{XRD}, \mathrm{Cr}_{2} \mathrm{O}_{3}$ was formed on the outer oxide layer and in the inner layer the oxides were mainly $\mathrm{Cr}_{2} \mathrm{O}_{3}$ and $\mathrm{CrNbO}_{4}$.

\section{ACKNOWLEDGEMENT}

This work was supported by the funds of Hunan Railway College of Science and Technology, the scientific research fund of Hunan Provincial Education Department. This work was partly supported by National Natural Science Foundation of China (Grant No. 50474009), the Aeronautical science foundation of China (Grant No. 05G56003), the Natural Science Foundation of Jiangxi province (Grant No. 0350045) and the Materials Science and Engineering Research Center of Jiangxi province (Grant No. ZX200401001).

\section{REFERENCES}

[1] Liu CT, Zhu JH, Brandy MP. Physical metallurgy and mechanical properties of transition-metal Laves phase alloys. Intermetallics 2000; 8: 1119-29.

[2] Thoma DJ, Nibur KA, Chan KC. The effect of alloying on the properties of (Nb,Ti) $\mathrm{Cr}_{2} \mathrm{C} 15$ Laves phases. Mater Sci Eng A 2002; 329-331: 408-15.

[3] Bewlay BP, Lewandowski JJ, Jackson MR. Refractory metalIntermetallic in situ. Composites for aircraft engines. JOM 1997; 40: 44-67.

[4] Jiang Chao. Site preference of early transition metal elements in $\mathrm{C} 15 \mathrm{NbCr}_{2}$. Acta Mater 2007; 55(5): 1599-05.

[5] Kazantzis VA, Aindow M, Jones IP, Triantafyllidis GKM De, Hosson JTH. The mechanical properties and the deformation microstructures of the $\mathrm{C} 15$ Laves phase $\mathrm{Cr}_{2} \mathrm{Nb}$ at high temperatures. Acta Mater 2007; 55: 1873-89.
[6] Takasugi T, Yoshida M, Hanada S. Deformability improvement in $\mathrm{C} 15 \mathrm{NbCr}_{2}$ intermetallics by addition of ternary elements. Acta Mater 1996; 44(2): 669-74.

[7] Yoshida M, Takasugi T. The alloying effect on the high temperature deformation of Laves phase intermetallic compound. Mater Sci Eng A 1997; 234-236: 873-6.

[8] Takasugi T, Yoshida M. The effect of ternary addition on structure and stability of $\mathrm{NbCr}_{2}$ Laves phases. J Mate Res 1998; 13(9): 250513.

[9] Chan KS. Alloying effects on fracture mechanisms in Nb-based intermetallic in situ composites. Mater Sci Eng A 2002; 329-31: 513-22.

[10] Davidson DL, Chan KS. The Effect of microstructure on the fracture resistance of Nb-Cr-Ti in situ composites. Scr Mater 1998; 38 : 1155-61.

[11] Yao Q, Sun J, Zhang Y, Jiang B. First-principles studies of ternary site occupancy in the $\mathrm{C} 15 \mathrm{NbCr}_{2}$ Laves phase. Acta Mater 2006; 54: 3585-91.

[12] Yoshida M, Takasugi T. Phase relation and microstructure of the Nb-Cr-W alloy system. Mater Sci Eng A 1999; 262: 107-14.

[13] Brady MP, Pint BA, Tortorelli PF, Wright IG. High-temperature oxidation and corrosion of intermetallics, In: Schutze M, Ed. Corrosion and environmental degration of materials. Weinheim, Wiley-VCH, Germany 2001.

[14] Kang PC, Yin ZD. Phase formation during annealing as-milled powders of molybdenum disilicide. Mater Lett 2003; 57: 4412-7.

[15] Ohta T, Nakagawa Y, Kaneno Y. Microstructures and mechanical properties of $\mathrm{NbCr}_{2}$ and $\mathrm{ZrCr}_{2}$ Laves phase alloys prepared by powder metallurgy. J Mater Sci 2003; 38: 657-65.

[16] Davidson DL, Chan KS. Microstructural and fracture characterization of $\mathrm{Nb}-\mathrm{Cr}-\mathrm{Ti}$ mechanically alloyed materials. Metal Mater Trans A 2002; 33: 401-16.

[17] Nie XW, Lu SQ, Wang KL. Phase transformations of $\mathrm{NbCr}_{2}$ intermetallics produced by mechanical alloying followed by hotpressing consolidation. Mater Charact 2008; 59: 816-9.

[18] Nie XW, Lu SQ, Wang KL. Effect of mechanical alloying on the structure and properties of $\mathrm{NbCr}_{2}$ Laves phase fabricated by hot pressing. Powder Technol 2008; 184: 333-6.

[19] Lillerud KP, Kofstad P. On high temperature oxidation of chromium. J Electrochem Soc 1980; 127: 2397-409.

[20] Hart EW. On the role of dislocation in bulk diffusion. Acta Met 1957; 5: 597-9. 